Research Article

\title{
Microstructure of Al-Si Slurry Coatings on Austenitic High-Temperature Creep Resisting Cast Steel
}

\author{
Agnieszka E. Kochmańska (i) \\ West Pomeranian University of Technology in Szczecin, Piastow 17, 70-310 Szczecin, Poland \\ Correspondence should be addressed to Agnieszka E. Kochmańska; agnieszka.kochmanska@zut.edu.pl
}

Received 30 September 2017; Revised 27 November 2017; Accepted 10 December 2017; Published 1 February 2018

Academic Editor: Yuanshi Li

Copyright @ 2018 Agnieszka E. Kochmańska. This is an open access article distributed under the Creative Commons Attribution License, which permits unrestricted use, distribution, and reproduction in any medium, provided the original work is properly cited.

\begin{abstract}
This paper presents the results of microstructural examinations on slurry aluminide coatings using scanning electron microscopy, X-ray microanalysis, and X-ray diffraction. Aluminide coatings were produced in air atmosphere on austenitic high-temperature creep resisting cast steel. The function of aluminide coatings is the protection of the equipment components against the high-temperature corrosion in a carburising atmosphere under thermal shock conditions. The obtained coatings had a multilayered structure composed of intermetallic compounds. The composition of newly developed slurry was powders of aluminium and silicon; $\mathrm{NaCl}, \mathrm{KCl}$, and $\mathrm{NaF}$ halide salts; and a water solution of a soluble glass as an inorganic binder. The application of the inorganic binder in the slurry allowed to produce the coatings in one single step without additional annealing at an intermediate temperature as it is when applied organic binder. The coatings were formed on both: the ground surface and on the raw cast surface. The main technological parameters were temperature $\left(732-1068^{\circ} \mathrm{C}\right)$ and time of annealing (3.3-11.7 h) and the Al/Si ratio (4-14) in the slurry. The rotatable design was used to evaluate the effect of the production parameters on the coatings thickness. The correlation between the technological parameters and the coating structure was determined.
\end{abstract}

\section{Introduction}

High-temperature corrosion is a common problem in various industrial processes, such as heat treatment, chemical processing, refining, etc. in, for example, petrochemical, aerospace, and gas turbine industries. Furnaces for thermochemical treatment, for example, carburising or nitriding furnaces, are often made of high-temperature creep resisting cast steels, especially Fe-Cr-Ni based alloys. A high mechanical strength at elevated temperatures and a resistance to thermal shocks are required from these materials. It is difficult to keep a satisfactory compromise between the mechanical strength and the surface degradation resistance in such severe working conditions. On the surface of $\mathrm{Cr}$-rich materials, a protective chromium oxide layer $\left(\mathrm{Cr}_{2} \mathrm{O}_{3}\right)$ is formed and provides the carburisation resistance at temperatures below $1050^{\circ} \mathrm{C}$ [1]. The chromia is also liable to spalling and cracking during creep and thermal shocks.
Therefore, the other protective layers such $\mathrm{SiO}_{2}$ and $\mathrm{Al}_{2} \mathrm{O}_{3}$ are considered. For oxidation resistance above $1200^{\circ} \mathrm{C}$, alloys that rely on the protective $\mathrm{Al}_{2} \mathrm{O}_{3}$ scale formation are preferred over those forming chromia. Unfortunately, the addition of aluminium and silicon to the high-temperature creep resisting alloys to develop full protection involves metallurgical compromise in strength and ductility. Therefore, silicon is usually limited to $2 \%$ and aluminium to less than $4 \%$ in alloys [2].

One of the most frequent solutions to introduce aluminium and silicon is an application of appropriate coatings. Inward diffusion of aluminium and outward diffusion of iron, nickel, and chromium results in the formation of intermetallic phases with very interesting properties. They are widely used for the improvement of the corrosion resistance of iron- and nickel-based alloys. Among these intermetallics, $\mathrm{Fe}$ and $\mathrm{Ni}$ aluminides improve the resistance to many aggressive environments including oxidising [3,4], sulphidising [5], and 
carburising $[6,7]$ agents. These coatings extend the lifetime of the equipment as a result of the carburisation reduction of the surface layer. Coatings, that protect the base material in industrial processes, need not only to inhibit the diffusion of elements, but also must offer resistance to thermal shocks that occur during quenching following the carburising process [8]. These shocks cause accelerated destruction of the protective coatings. In addition to aluminium in the coating, very important is the presence of silicon, which decreases the carbon solubility in austenite and is one of the main elements improving the resistance to carbon absorption at high temperatures. Moreover, it has been observed that $\mathrm{SiO}_{2}$ is present as a subscale beneath chromium oxide [1].

The manufacturing method of the coating should be easy to apply on complex-shaped parts, and the cost should be as low as possible. One of these methods is the slurry cementation. Slurry aluminisation can provide advantages in the process, that is, simplicity and economical efficiency. Typical slurries manufactured on the base of aluminium powder (as an active component) and of the solution of an organic binder are widely used [9-12]. When the polyvinyl alcohol is used as the organic binder in the slurry, slurrycoated specimens have to be held at a temperature of $300^{\circ} \mathrm{C}$ for $4 \mathrm{~h}$ [12] or $400^{\circ} \mathrm{C}$ for $3 \mathrm{~h}$ [10] to expel the binder and only after that heat treated. The use of the other type of binder instead of the organic one could allow to produce the coatings in an one single step without additional annealing at an intermediate temperature.

In this work, a single-step slurry cementation was applied to create the protective Al-Si coatings. The method used by the author is a modification of the conventional one. In this study, the inorganic binder, that is, a water solution of sodium silicate, was applied instead of the organic one. The simultaneous use of the sodium silicate and the silicon powder in the slurry causes dehydration and self-hardening of the slurry. This means that silicon can be beneficial in the slurry both from a technological point of view and later in the diffusion-forming process. The innovative composition of the slurry has forced the determination of optimum production parameters of the protective coatings on austenitic high-temperature creep resisting cast steel.

The slurry usually comprises metal powders with a grain size below $40 \mu \mathrm{m}$ [13], but very often the grain size is in the order of a few micrometers $[14,15]$. In this work, powders of larger granularity were used. This has reduced the cost of the slurry. In addition, a larger grain of aluminium powder reduces the risk of an explosion during production.

Additionally, in this work, a mixture of three selected salts was used. These salts applied in the slurry are a flux and have good properties from an ecological and economic point of view. The existence of oxides on both aluminium particles in the slurry and the surface of samples is a barrier for diffusion processes. The oxide shell is dissolved by this flux during annealing. The coating is formed in a liquid state (the temperature of annealing is above the temperature of aluminium melting). The liquid state guarantees high rates of the diffusion reaction, and the interruption of the oxide shell accelerates processes in the liquid state.

\section{Materials and Methods}

2.1. Samples and Slurry Composition. The substrate used for the investigation was austenitic high-temperature creep resistant cast steel (GX20NiCrSi30-18-1) containing approximately 0.2 wt. $\% \mathrm{C}, 18 \% \mathrm{Cr}, 30 \% \mathrm{Ni}, 0.7 \% \mathrm{Mn}, 1.5 \% \mathrm{Si}$, $0.03 \%$ P, $0.03 \%$ S, and Fe balance. Dimensions of the samples were $10 \times 20 \times 6 \mathrm{~mm}$. The surface of samples used in the experiment was finished by grinding. However, several samples of the raw cast surface were subjected to produce the coatings as well (to verify the possibility of the coating formation). The wall thickness of the casting was about $9 \mathrm{~mm}$; therefore, the dimensions of this sample were $10 \times 20 \times 9 \mathrm{~mm}$. The active slurry was prepared from silicon and aluminium powders. The grain size was approximately $100 \mu \mathrm{m}$ for the aluminium powder and within the range $200-250 \mu \mathrm{m}$ for the silicon powder. The binder used in the slurry consisted of an aqueous solution of sodium silicate (soluble glass). The flux was used of composition of sodium and potassium salts $(\mathrm{NaF}, \mathrm{NaCl}$, and $\mathrm{KCl})$. The ratio of the sodium silicate to $(\mathrm{Al}+\mathrm{Si})$ powders was $15 / 100$, and the ratio of the salts to $(\mathrm{Al}+\mathrm{Si})$ powders was $9.5 / 100$. The quantitative composition of the slurry was determined experimentally and patented [16].

The samples after degreasing with acetone were immersed several times in the water slurry and dried until the value of the covering mass amounted to $0.3 \mathrm{~g} \cdot \mathrm{cm}^{-2}$ and then annealed in air atmosphere (without any protective atmosphere). The slurry residues were removed after annealing, and the samples were washed in an ultrasonic bath in acetone.

2.2. Design of Experiment. The purpose of the application of the plan is the determination of the optimum parameters of coatings producing. The annealing temperature, time, and the ratio $\mathrm{Al} / \mathrm{Si}$ in the slurry were adopted as three independent variables in the design of the experiment. The determination of the equations describing the thickness as a function of these three parameters was the objective in the chosen experiment design. A rotatable central composite design was chosen. Thus, rotatable designs do not favour one direction over another during exploring. This is reasonable when the knowledge about the response surface before experimentation is insufficient. This design requires twenty interactions (total points in the design) if there are three variable parameters [17]. The various combinations of levels of these interactions lie on the edge (factorial) points $( \pm 1, \pm 1$, $\pm 1)$ and the centre point $(0,0,0)$ of a cubic experimental region, as illustrated schematically in Figure 1.

The plan assumes the existence of additional (axial) points $( \pm \alpha, 0,0),(0, \pm \alpha, 0)$, and $(0,0, \pm \alpha)$. In the rotatable design, the variance of the predicted response is the same at all points that have the same distance from the centre of the design. The plan of the rotatable design for the coded variables $\left(x_{i}\right)$ together with all the real values $\left(X_{i}\right)$ of the interaction between the three variables is shown in Table l. It was assumed that the unknown characteristics can be approximated by the second-order model which describes 


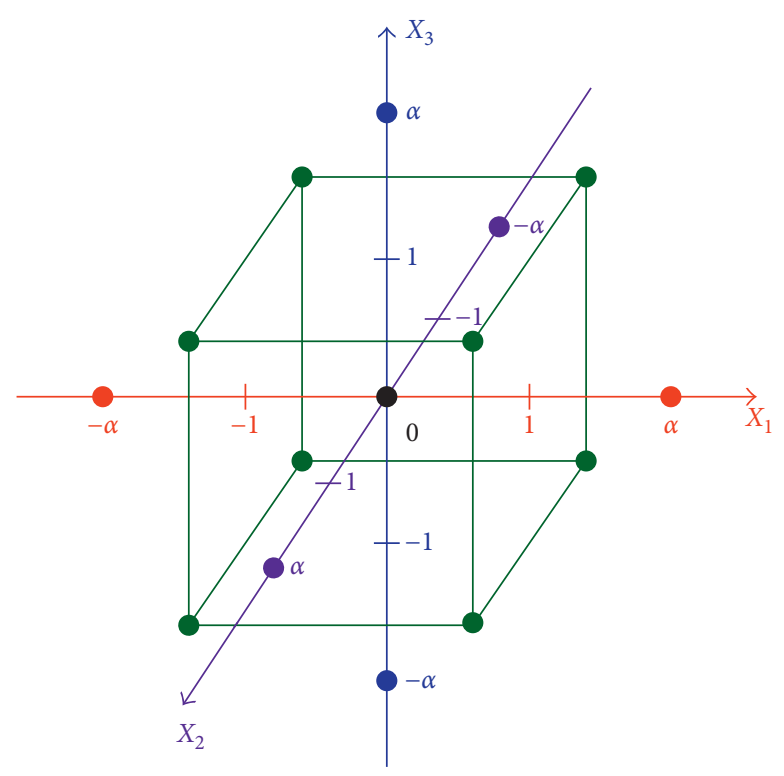

FIGURE 1: Graphical representation of the rotatable design for the three variables.

TABLE 1: The rotatable design for three-factor interactions with coded and real variables.

\begin{tabular}{|c|c|c|c|c|c|c|}
\hline \multirow{2}{*}{ Run number/number of coating } & \multicolumn{2}{|c|}{ Temperature } & \multicolumn{2}{|c|}{ Time } & \multicolumn{2}{|c|}{ Ratio Al/Si } \\
\hline & $x_{1}$ & $X_{1} /{ }^{\circ} \mathrm{C}$ & $x_{2}$ & $X_{2} / \mathrm{h}$ & $x_{3}$ & $X_{3}$ \\
\hline 1 & -1 & 800 & -1 & 5 & -1 & 6 \\
\hline 2 & +1 & 1000 & -1 & 5 & -1 & 6 \\
\hline 3 & -1 & 800 & +1 & 10 & -1 & 6 \\
\hline 4 & +1 & 1000 & +1 & 10 & -1 & 6 \\
\hline 5 & -1 & 800 & -1 & 5 & +1 & 12 \\
\hline 6 & +1 & 1000 & -1 & 5 & +1 & 12 \\
\hline 7 & -1 & 800 & +1 & 10 & +1 & 12 \\
\hline 8 & +1 & 1000 & +1 & 10 & +1 & 12 \\
\hline 9 & -1.682 & 732 & 0 & 7.5 & 0 & 9 \\
\hline 10 & +1.682 & 1068 & 0 & 7.5 & 0 & 9 \\
\hline 11 & 0 & 900 & -1.682 & 3.3 & 0 & 9 \\
\hline 12 & 0 & 900 & +1.682 & 11.7 & 0 & 9 \\
\hline 13 & 0 & 900 & 0 & 7.5 & -1.682 & 4 \\
\hline 14 & 0 & 900 & 0 & 7.5 & +1.682 & 14 \\
\hline 15 & 0 & 900 & 0 & 7.5 & 0 & 9 \\
\hline 16 & 0 & 900 & 0 & 7.5 & 0 & 9 \\
\hline 17 & 0 & 900 & 0 & 7.5 & 0 & 9 \\
\hline 18 & 0 & 900 & 0 & 7.5 & 0 & 9 \\
\hline 19 & 0 & 900 & 0 & 7.5 & 0 & 9 \\
\hline 20 & 0 & 900 & 0 & 7.5 & 0 & 9 \\
\hline
\end{tabular}

quadratic surfaces, and quadratic surfaces can take several shapes [17]. Second-order model for three independent variables takes the form

$$
\begin{aligned}
Y=\beta_{0} & +\beta_{1} X_{1}+\beta_{2} X_{2}+\beta_{3} X_{3}+\beta_{4} X_{1}^{2}+\beta_{5} X_{2}^{2} \\
& +\beta_{6} X_{3}^{2}+\beta_{7} X_{1} X_{2}+\beta_{8} X_{1} X_{3}+\beta_{9} X_{2} X_{3} .
\end{aligned}
$$

A second-order design has a uniform precision which is a reasonable criterion, because we want to know precision how close to the origin a maximum or other surface feature may be [17].

The central temperature, the central annealing time, and the central ratio $\mathrm{Al} / \mathrm{Si}$ were correspondingly $900^{\circ} \mathrm{C}, 7.5$ hours and $9: 1$, respectively. The remaining points $( \pm 1, \pm \alpha)$ were 


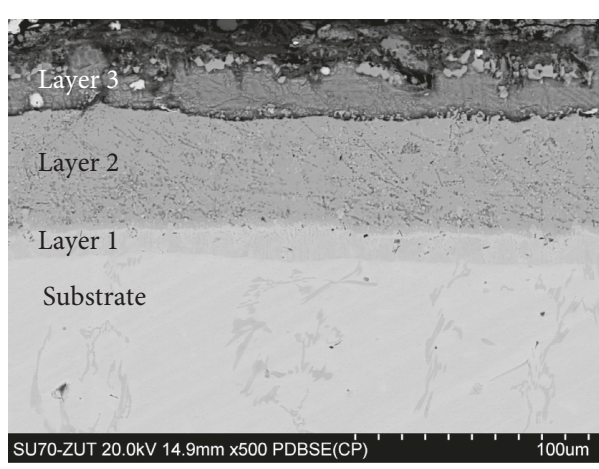

(a)

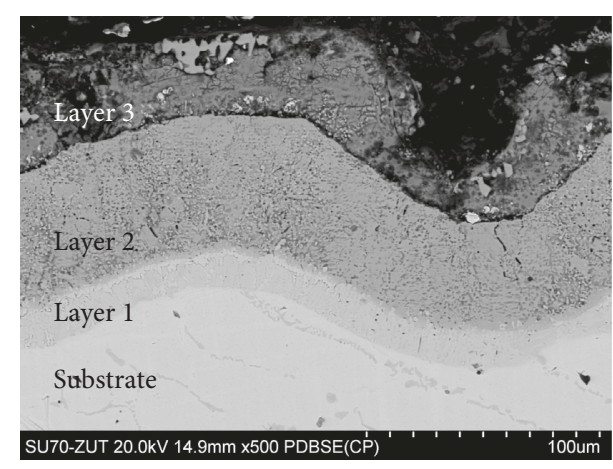

(b)

Figure 2: Microstructure (BEI) of Al-Si coating on sample (a) number 16 (surface after grinding), (b) with a rough cast surface (technological parameters in both cases: $900^{\circ} \mathrm{C}, 7.5 \mathrm{~h}, \mathrm{Al} / \mathrm{Si}=9$; central point of the experiment).

calculated assuming an appropriate step. The steps (levels coded as \pm 1 ) for the temperature, time, and ratio $\mathrm{Al} / \mathrm{Si}$ were correspondingly $\pm 100, \pm 2.5$, and \pm 3 , respectively. The ratio $\mathrm{Al} / \mathrm{Si}$ in the slurry was changed from $4: 1$ to $14: 1$. The samples covered with the slurry were annealed at corresponding temperatures between $732^{\circ} \mathrm{C}$ and $1068^{\circ} \mathrm{C}$ for corresponding times between 3.3 and 11.7 hours, respectively, in the air atmosphere. The design predicted the coating properties throughout the area, even at parameter combinations actually not working. The properties of coatings are predicted for the whole range of the three parameters using only the parameter combinations considered.

2.3. Microstructural Characterization. Metallographic preparations of the cross sections of all coatings were conducted according to the standard methods. All samples have been examined using the field emission scanning electron microscopy (FESEM) (Hitachi SU-70) equipped with the energy dispersive X-ray microanalysis (EDS; Thermo Scientific NORAN System 7). Accelerating voltage of $20 \mathrm{kV}$ was applied for SEM and EDS analyses. The COMPASS software was used by collecting a complete, deadtime-corrected spectrum at every point of the sample. COMPASS is a statistical-based software applied in the Thermo NORAN 7 software which enables quantitative analysis of each elemental phase [18]. The COMPASS software finds image locations that have the same spectral "fingerprint," with no assumptions about the chemical composition of the sample. Such created elemental phase maps show the spatial distribution of regions that have statistically similar spectral features (peak locations and relative peak heights) and cumulative spectra of these regions.

The XRD analysis was conducted with Panalytical X'Pert-PRO X-ray diffractometer using Co-K $\alpha$ radiation and the HighScore software to analyse the diffraction patterns. Consecutive layers of the coating material were removed by grinding. Such a protocol enabled to identify phase components present in particular layers.

The microhardness tests were performed using a Buehler hardness tester using a Knoop indenter at the load of 0,098 N during $15 \mathrm{~s}$.

\section{Results and Discussion}

The coatings were successfully produced for each set of assumed technological parameters. The microscopic observations proved that the microstructures of the coatings depended on the production parameters. In general, the typical coating consisted of three layers: the internal layer (1), the middle layer (2), and the external layer (3) (Figure 2(a)). The total thickness of the resulting coatings for particular cases was rather uniform, and the standard deviations did not exceed 5\%, except the coatings produced at a low temperature, especially in a long time, which were less uniform (the standard deviations did not exceed 10\%).

The microstructure of the coating obtained with the central technological parameters $\left(900^{\circ} \mathrm{C}, 7.5 \mathrm{~h}, 9 \mathrm{Al} / \mathrm{Si}\right)$ is shown in Figure 2. Figure 2(a) shows the Al-Si coating obtained on the surface after grinding and Figure 2 (b) on the raw cast surface. No significant differences in microstructure between the coatings on the machined and the raw cast surface were observed. Thus, the coatings can be produced on the cast surface without further mechanical processing like grinding [19]. The possibility to obtain coatings on the surface of the raw cast is very important from the technological point of view. The presence of the flux in the slurry promotes the formation of the coating despite the existence of a thick oxide layer on the surface of the casting.

Different structures and properties of the coatings were obtained depending on the technological parameters in the established plan of the experiment. For example, the structures of the two coatings prepared with the parameters belonging to set numbers 7 and 2 are shown in Figures 3(a) and 3(b), respectively. The main differences in the structure of the coatings were the thickness and the chemical composition.

The relations (as regression models) between the thickness and various parameters were determined using Statistica 12 software, and the equations thus obtained are presented below. The following notation was used: $Y_{x}$, the thickness of the $x$ sublayer $(\mu \mathrm{m}) ; Y_{t}$, the total thickness $(\mu \mathrm{m})$; $X_{1}$, the annealing temperature $\left({ }^{\circ} \mathrm{C}\right) ; X_{2}$, the annealing time (h); $X_{3}$, the Al/Si ratio; $R$, multiple correlation coefficient; $R^{2}$, unbiased estimator; $F$, value of Snedecor test. 


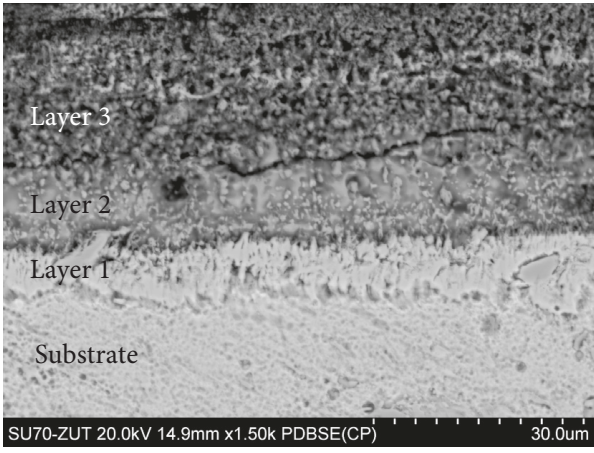

(a)

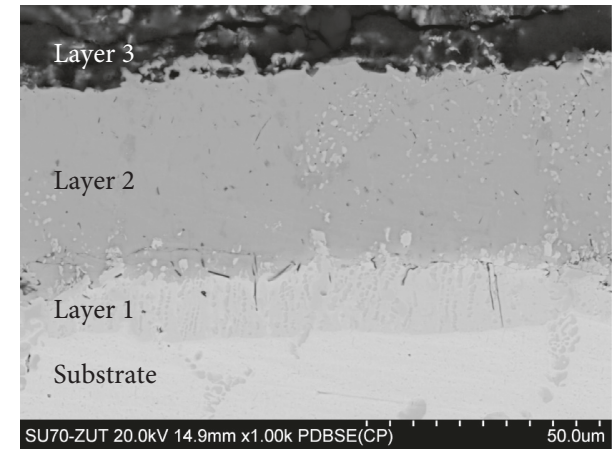

(b)

Figure 3: Microstructure (BEI) of Al-Si coating on sample (a) number 7 (technological parameters: $800^{\circ} \mathrm{C}, 10 \mathrm{~h}, \mathrm{Al} / \mathrm{Si}=12$ ) and (b) number 2 (technological parameters: $1000^{\circ} \mathrm{C}, 5 \mathrm{~h}, \mathrm{Al} / \mathrm{Si}=6$ ).

$$
\begin{aligned}
& Y_{1}=523-1.07 X_{1}-30 X_{2}+0.0006 X_{1}^{2} \\
& +0.56 X_{2}^{2}+0.026 X_{1} X_{2} \\
& R=0.96 ; R^{2}=0.93 ; \quad F=36.78 \\
& Y_{2}=43.3-3.89 X_{2} X_{3}+0.005 X_{1} X_{2} X_{3} \\
& R=0.72 ; R^{2}=0.52 ; \quad F=9.23 \\
& Y_{3}=-6.68+0.008 X_{1} X_{2} \\
& R=0.65 ; R^{2}=0.42 ; \quad F=13.42 \\
& Y_{t}=-206.94+0.00035 X_{1}^{2}+0.966 X_{2}^{2} \\
& R=0.78 ; R^{2}=0.60 ; \quad F=12.80 .
\end{aligned}
$$

The determined regression models for the thickness were used to show the dependence on the annealing time and the temperature in the following graphs (Figure 4). The total thickness (5) of the coatings and the thickness of each layer depended mainly on the temperature and the time of the annealing. The ratio of aluminium to silicon in the slurry only affected the thickness of the second layer (3). Hence, the $\mathrm{Al} / \mathrm{Si}$ ratio had no significant influence on the thickness of the first and third layers (in the applied range). The graph of the second layer thickness has been drawn for the Al/Si ratio $X_{3}=6$. It was found that the total thickness of the coating increased with increasing temperature and time of annealing (Figure $4(\mathrm{~d}))$. The same holds for the thickness of the third layer (Figure 4(c)). The situation was different using the regression models representing the thickness of the first and the second layer. The increase in the thickness of these layers is apparent with increasing temperature and the time, but only at temperatures above $900^{\circ} \mathrm{C}$. The thickness of the first and the second layer decreased significantly with the increasing times at temperatures below $800^{\circ} \mathrm{C}$.

The Knoop hardness measurement results performed in layers 1 and 2 and in the base material were correspondingly $784 \pm 137 \mathrm{HK} 0.01$ in the first layer, $1251 \pm 224 \mathrm{HK} 0.01$ in the second layer, and $436 \pm 68 \mathrm{HK} 0.01$ in the base material. The results of the coating hardness measurements showed that the first layer has an intermediate hardness value in between those of the substrate and the second layer reducing the stress gradient between the substrate and the coating. The third layer was brittle at room temperature, and hardness tests have not been successfully performed. The spalling of the third layer occurring probably during metallographic preparation was observed, especially in coatings where the thickness of first and the second layer was small and third layer was big (Figure 4(c) - in a long time of annealing).

Figure 5 shows the elemental mapping of the coating obtained at central parameters of the experiment design. The results of a quantitative point analysis (EDS) for the first layer and the second layer of the coatings are presented in Figures 6(a) and 6(b) and Table 2.

Quasiphase maps by the COMPASS procedure showed the spatial distribution of regions that have statistically similar spectral features (Figure 7). The results of the chemical quantitative analysis of each phase suggested by the COMPASS software are given in Table 3.

XRD phase analysis was performed on sections parallel to the surface of the coating, and subsequent XRD patterns are shown in Figure 8.

$\mathrm{AlN}, \mathrm{Al}_{5} \mathrm{FeNi}$, and $\beta$-NiAl phases were found near the surface of the coating formed at $1000^{\circ} \mathrm{C}$. The $\beta$-NiAl phase was identified in the second layer of this coating, and the $\alpha$ - $(\mathrm{Fe}, \mathrm{Cr}, \mathrm{Si})$ solution and $\mathrm{CrSi}_{2}$ were identified in the first layer. Alloyed austenite was identified in the substrate. XRD studies were also carried out for the coatings formed at a temperature of $800^{\circ} \mathrm{C}$, because the morphology of these coatings (formed at $800^{\circ} \mathrm{C}$ ) was slightly different from those formed at $1000^{\circ} \mathrm{C}$ (Figures $3(\mathrm{a})$ and $3(\mathrm{~b})$ ). It was also observed that the kinetics of growth of the first and the second layer at a temperature of $800^{\circ} \mathrm{C}$ differs from the kinetics of growth of these layers annealed at higher temperature (Figures 4(a) and 4(b)). A decrease in thickness with time was observed at annealing temperature of $800^{\circ} \mathrm{C}$. Figures 9 and 10 show XRD diffraction patterns of two coatings produced at $800^{\circ} \mathrm{C}$ for 10 hours but using different slurry compositions.

AlN phase was observed in the surface layer of the coating produced from the slurry with the ratio of $\mathrm{Al} / \mathrm{Si}=6$ (the amount of the silicon in the slurry is higher). In the 


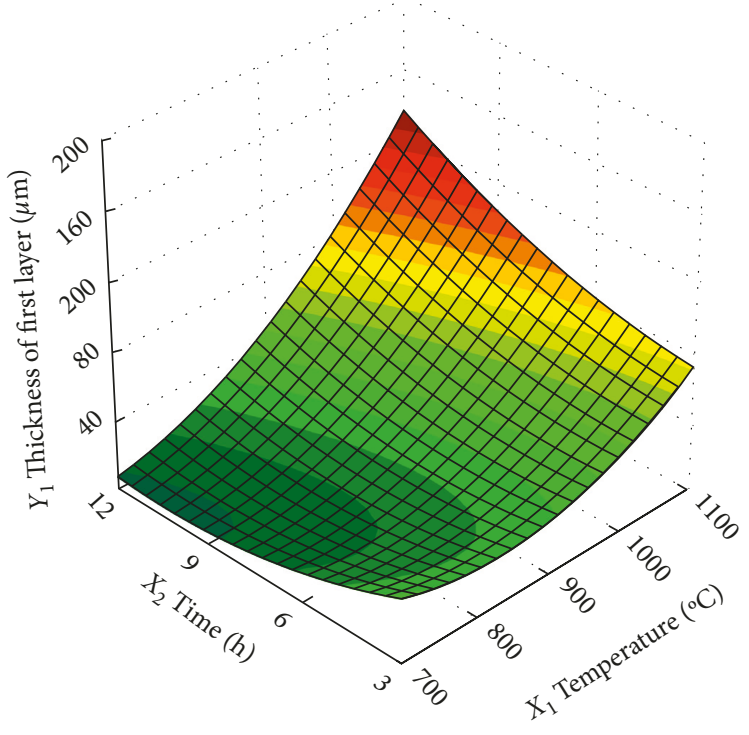

(a)

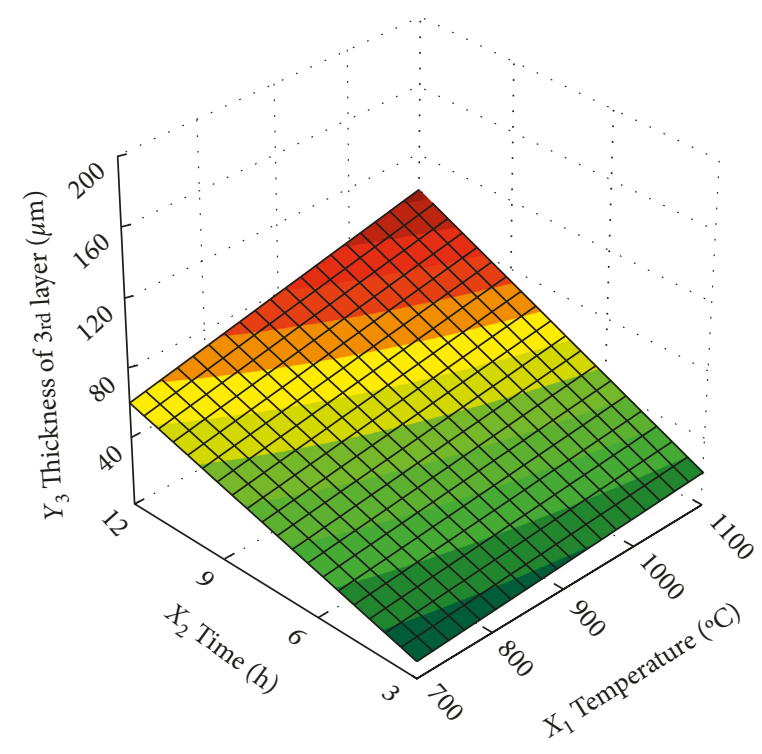

(c)

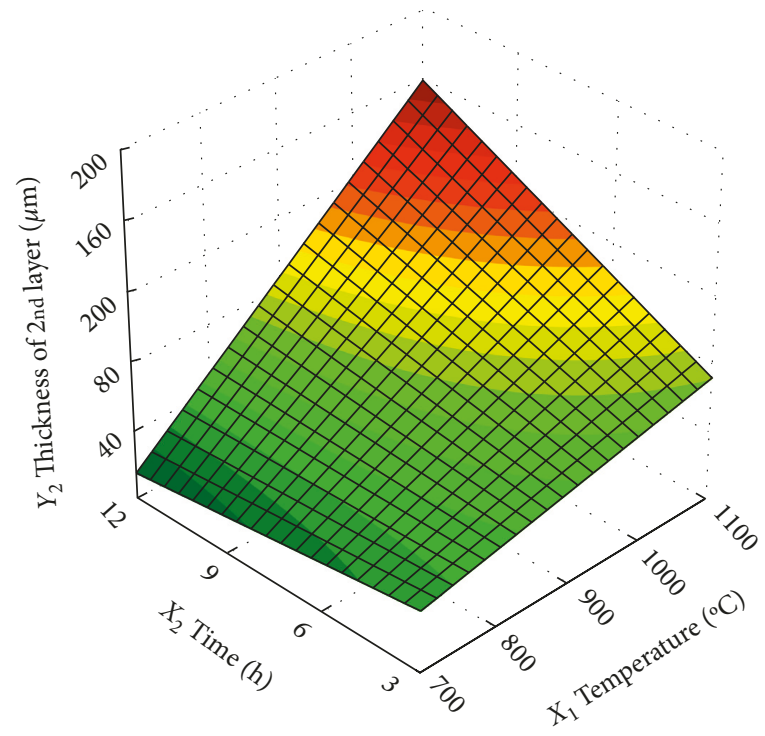

(b)

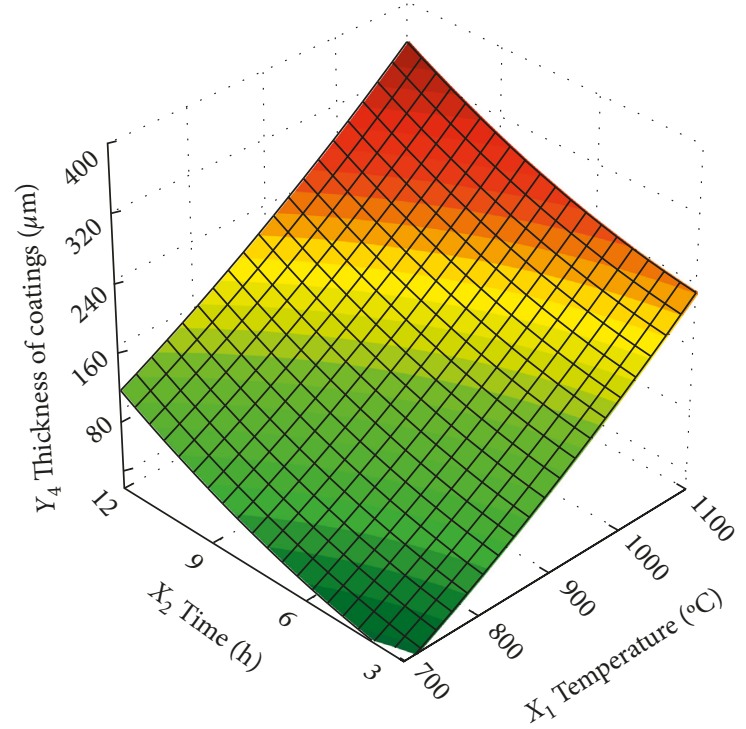

(d)

FIGURE 4: Graph of the correlation between the technological parameters and the thickness of (a) first layer, (b) second layer, (c) third layer, and $(\mathrm{d})$ coatings.

second and the third layers, $\mathrm{Al}_{5} \mathrm{FeNi}, \mathrm{Cr}(\mathrm{Al}, \mathrm{Si})_{2}, \mathrm{Al}_{3} \mathrm{Ni}_{2}$, and $\beta$-AlNi phases were identified. The $\mathrm{Al}_{5} \mathrm{FeNi}$ phase dominated in the third layer and the $\mathrm{Al}_{3} \mathrm{Ni}_{2}$ and $\beta$-AlNi phases in the second layer. The $\alpha-(\mathrm{Fe}, \mathrm{Cr}, \mathrm{Si})$ solution in the first layer was identified. $\mathrm{Cr}(\mathrm{Al}, \mathrm{Si})_{2}, \mathrm{Al}_{8} \mathrm{Cr}_{5}, \mathrm{Al}_{3} \mathrm{Ni}_{2}$, and $\beta$-AlNi phases were observed near the surface of the coating produced from the slurry with the ratio of $\mathrm{Al} / \mathrm{Si}=12$. $\mathrm{Cr}(\mathrm{Al}$, $\mathrm{Si})_{2}, \mathrm{Al}_{3} \mathrm{Ni}_{2}$, and $\beta$-AlNi were in the third and second layers. The $\alpha$-(Fe, $\mathrm{Cr}, \mathrm{Si})$ solution was observed in the first layer similar to the previously described cases. The presence of $\mathrm{M}_{7} \mathrm{C}_{3}$ carbides from the substrate was also visible in the coating.

The first layer was a diffusion layer formed by outward iron diffusion and inward diffusion of silicon. Nickel diffusion from this area to the second layer led to Ni content decrease in the first layer, consequently promoting a transition of f.c.c. to b.c.c. crystal lattice. The $\gamma$-(Fe, Ni, Cr) solution transformed into the $\alpha$ - $(\mathrm{Fe}, \mathrm{Cr}, \mathrm{Si})$ solution [20], with a certain content of nickel and aluminium. The solubility of aluminium in $\gamma$-Fe is rather small contrary to that of $\alpha$-(Fe, $\mathrm{Cr})$ [21]. The aluminised coatings obtained at $1000^{\circ} \mathrm{C}$ in this work consisted of similar phase compositions to coatings with interfacial layers of the $\alpha$ - $(\mathrm{Cr}, \mathrm{Fe})$ and $\beta$-FeAl layers and the $\beta$-FeAl layer and a thick outer layer of $\delta$ - $\mathrm{Fe}_{2} \mathrm{Al}_{5}$ reported by $\mathrm{Hu}$ et al. [22]. They also observed [22] spherical $\beta$-FeAl precipitates present in the $\alpha-(\mathrm{Cr}, \mathrm{Fe})$ grains. In the current work, a fine-grained intermetallic $\beta-\mathrm{Al}(\mathrm{Ni}, \mathrm{Fe})$ phase was formed in the matrix of the first layer containing 

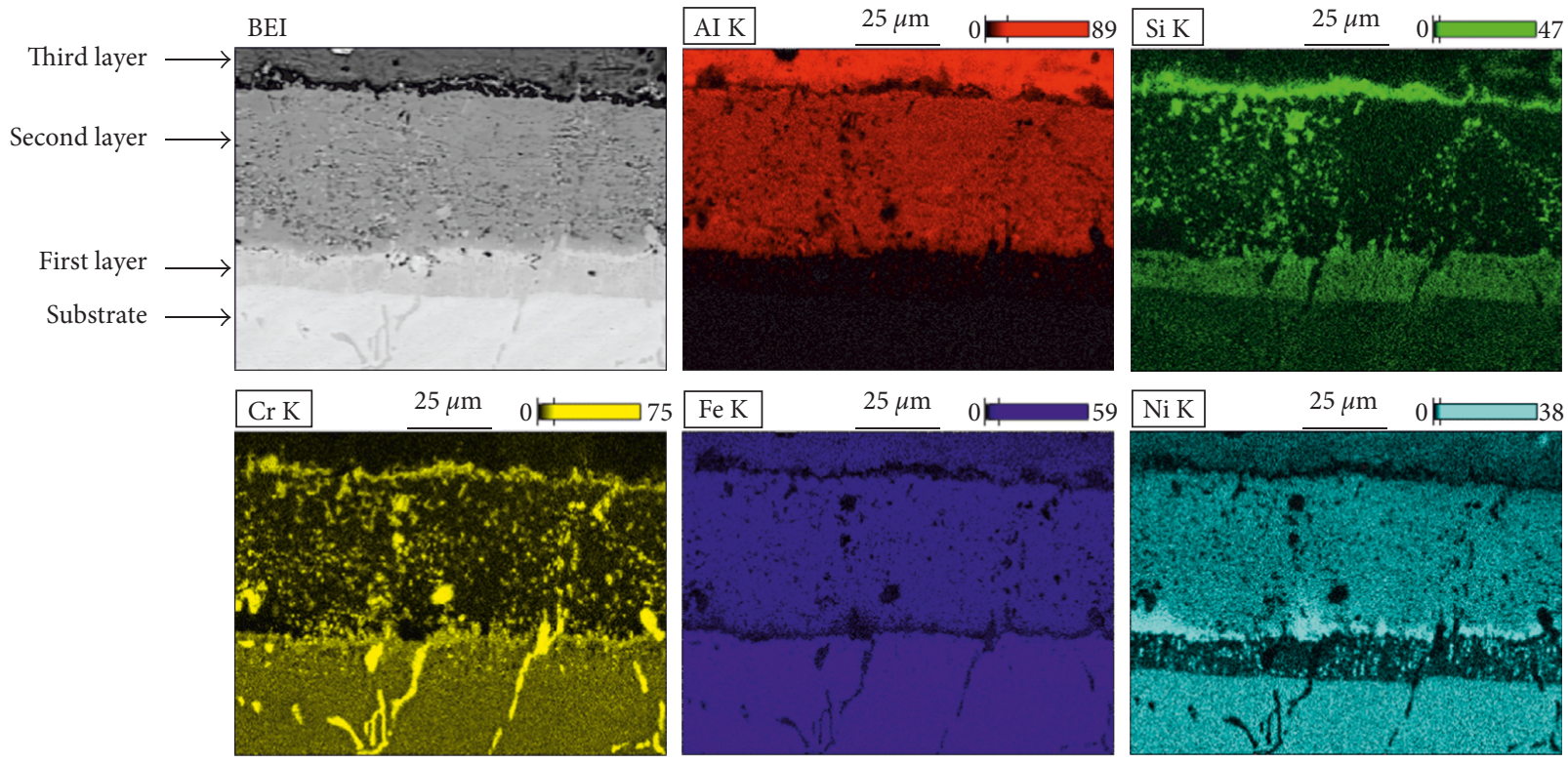

FIGURE 5: Elemental mapping in a cross section in coating number 17 (technological parameters $900^{\circ} \mathrm{C}, 7.5 \mathrm{~h}, \mathrm{Al} / \mathrm{Si}=9$; central point of the experiment).

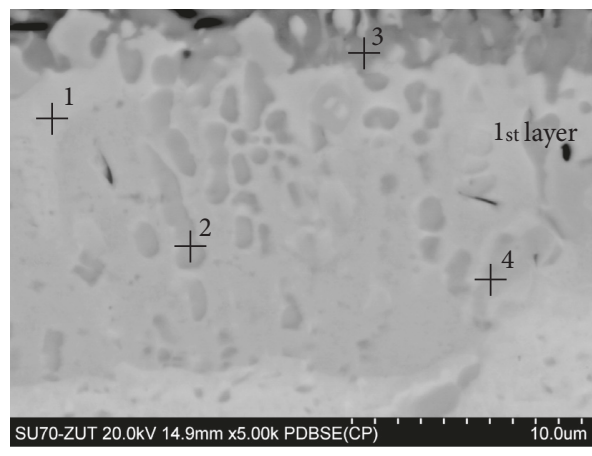

(a)

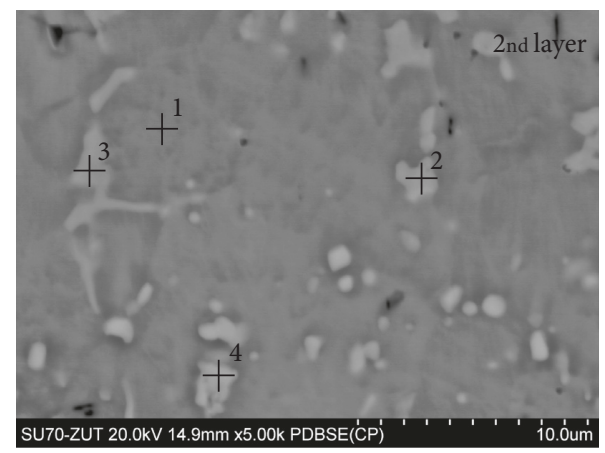

(b)

Figure 6: Microstructure (BEI) of (a) the first layer and (b) the second layer of the coating no. 4 obtained at temperature $1000^{\circ} \mathrm{C}$ in $10 \mathrm{~h}$ $(\mathrm{Al} / \mathrm{Si}=6)$ with points of EDS X-ray microanalysis.

TABle 2: Chemical composition according to Figures 6(a) and 6(b).

\begin{tabular}{|c|c|c|c|c|c|c|c|c|}
\hline \multirow{2}{*}{ Element } & \multicolumn{4}{|c|}{ Chemical composition (\%at.), according to Figure 6(a) } & \multicolumn{4}{|c|}{ Chemical composition (\% at.), according to Figure 6(b) } \\
\hline & Point 1 & Point 2 & Point 3 & Point 4 & Point 1 & Point 2 & Point 3 & Point 4 \\
\hline $\mathrm{Al}$ & 5.7 & 39.5 & 44.0 & 10.1 & 47.0 & 16.5 & 6.1 & 16.7 \\
\hline $\mathrm{Si}$ & 10.1 & 2.7 & 0.2 & 1.4 & 5.2 & 28.1 & 33.0 & 19.1 \\
\hline $\mathrm{Cr}$ & 29.9 & 6.3 & 8.0 & 48.8 & 4.0 & 32.4 & 48.6 & 42.7 \\
\hline $\mathrm{Fe}$ & 44.9 & 17.3 & 12.8 & 21.6 & 24.4 & 15.5 & 10.4 & 13.8 \\
\hline $\mathrm{Ni}$ & 9.5 & 34.2 & 35.0 & 18.2 & 19.4 & 7.6 & 1.9 & 7.5 \\
\hline
\end{tabular}

the $\alpha$ - $(\mathrm{Fe}, \mathrm{Cr}, \mathrm{Si})$ phase, as well. The $\beta$ - $\mathrm{Al}(\mathrm{Ni}, \mathrm{Fe})$ precipitates had spherical shapes (Figure 6(a), Table 2, point 2). The amount of nickel in the $\beta-\mathrm{Al}(\mathrm{Ni}, \mathrm{Fe})$ precipitates from first layer was significantly higher than that in the $\beta-\mathrm{Al}(\mathrm{Fe}, \mathrm{Ni})$ phase from the second layer (Table 3 , phase 3 and phase 4 ).
It was found that, with increasing production temperature, the thickness of the first layer increased, and simultaneously, a thin sublayer rich in nickel was formed at the boundary with the second layer (Figure 7, Table 3, phase 4). This sublayer had nearly the same chemical and phase 

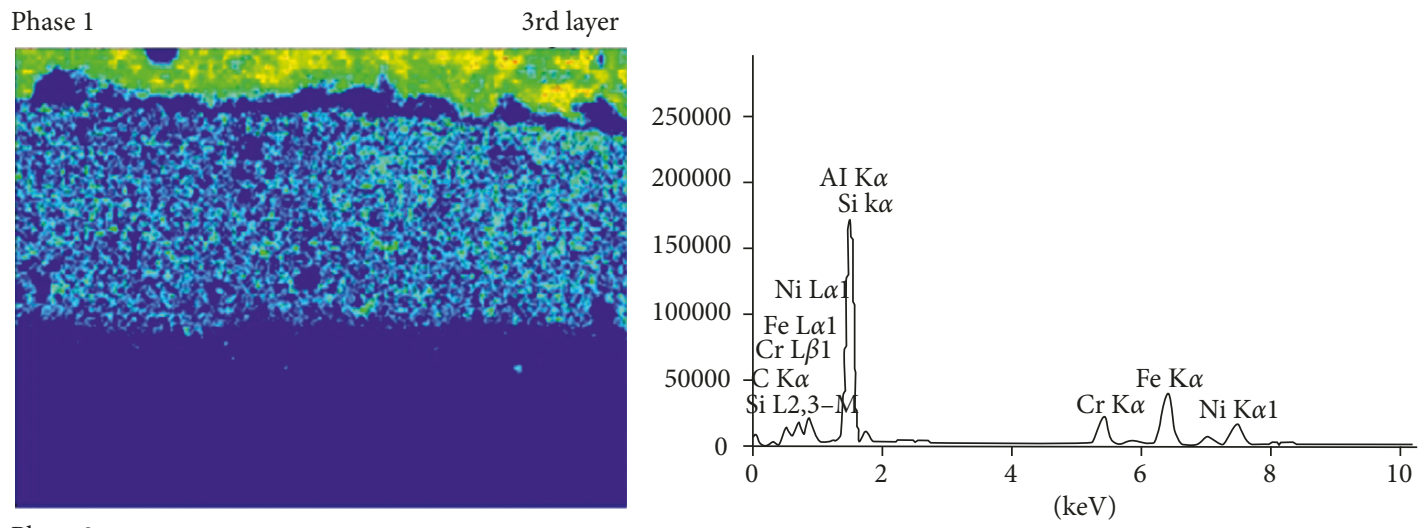

Phase 2
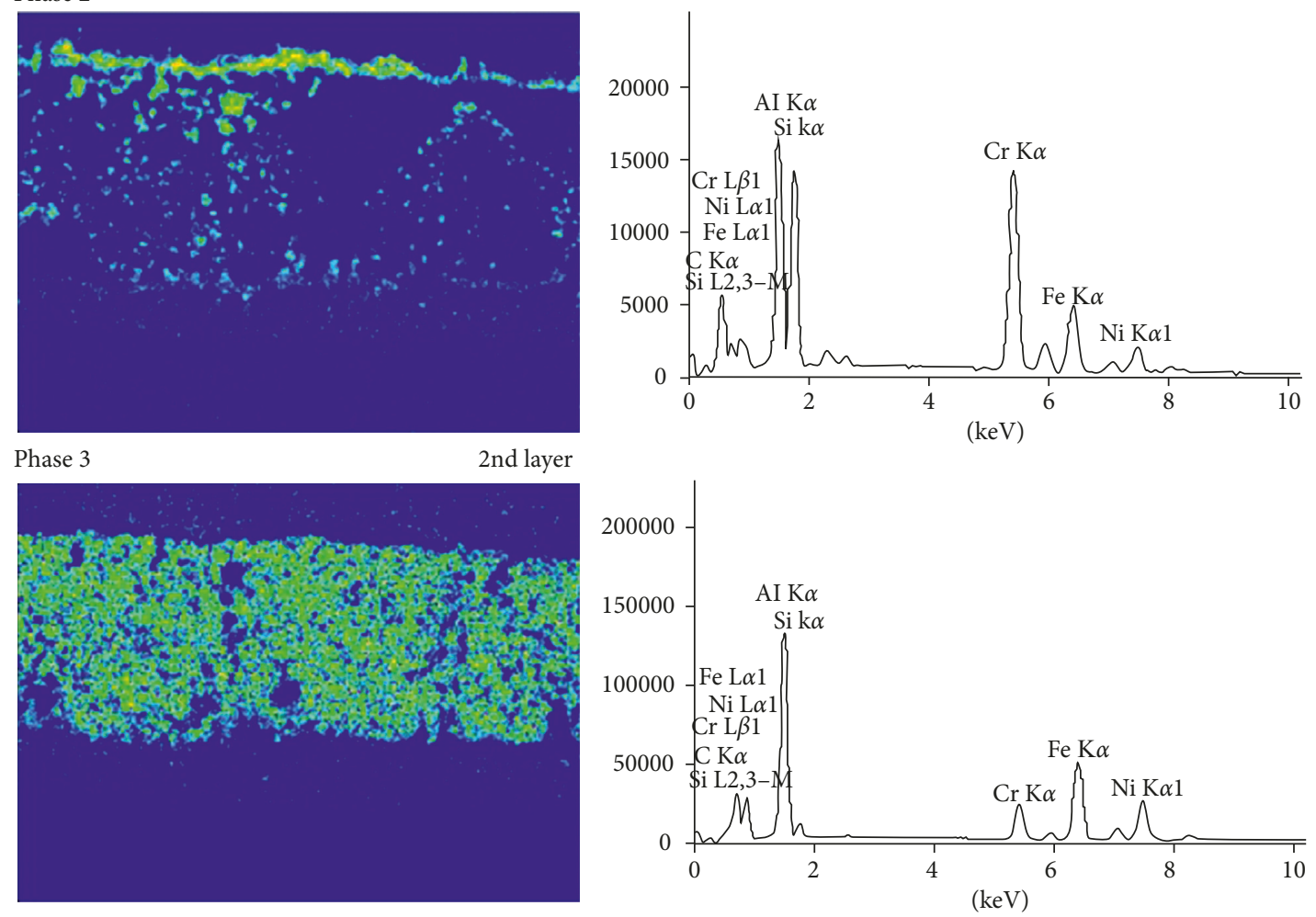

Phase 4
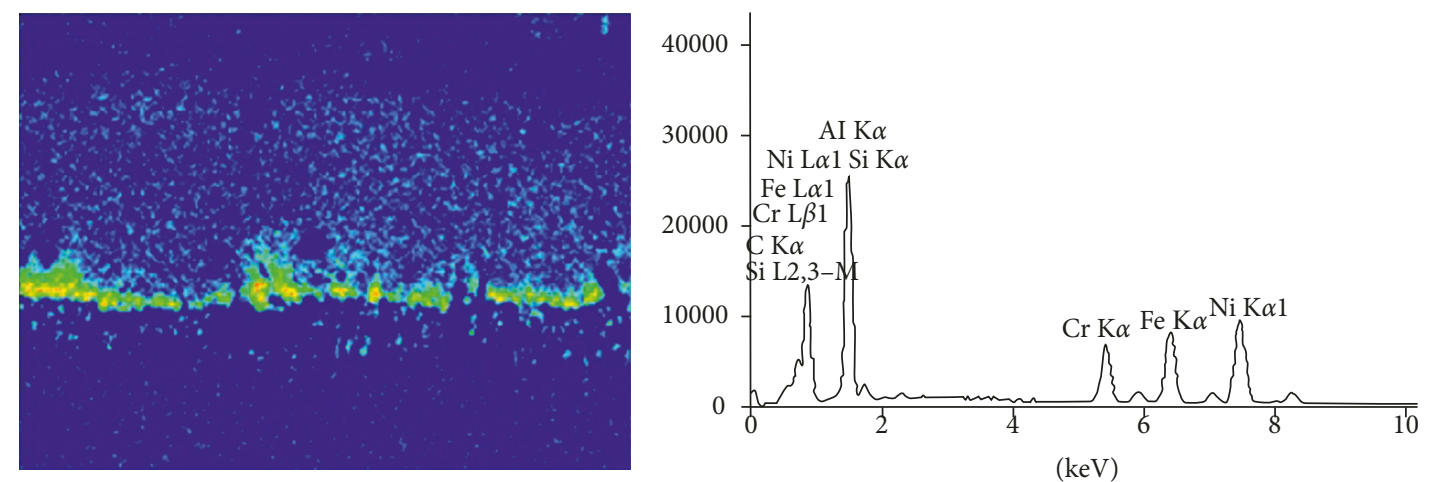

FIgUre 7: Continued. 


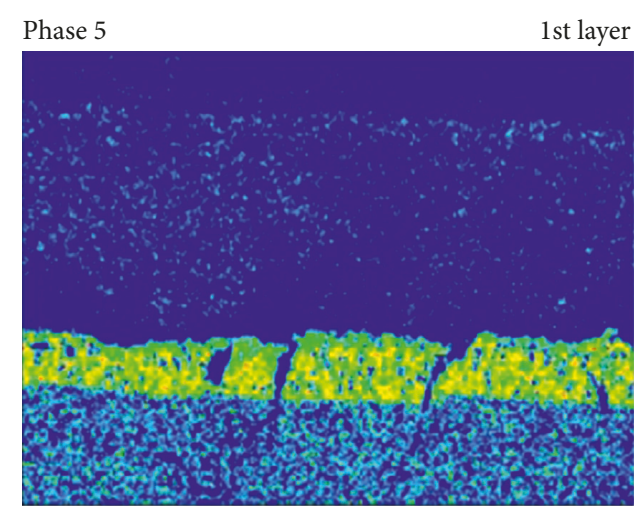

Phase 6

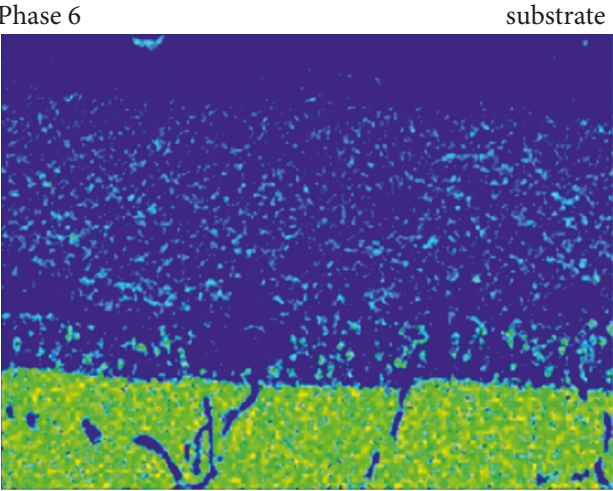

Phase 7

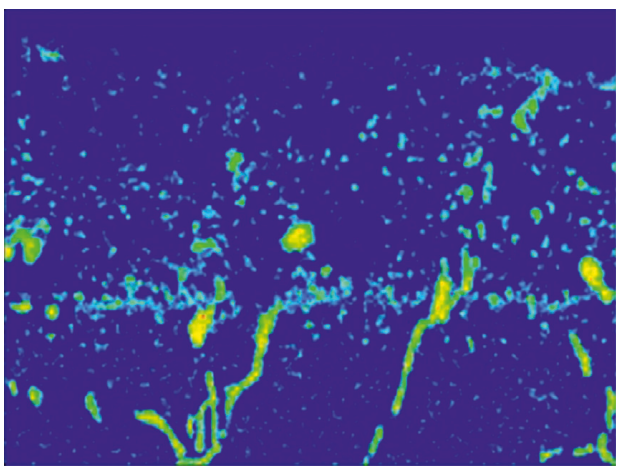

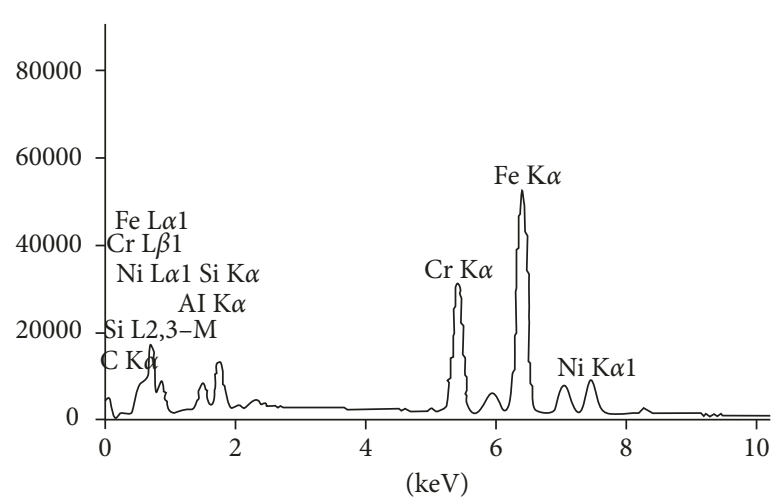

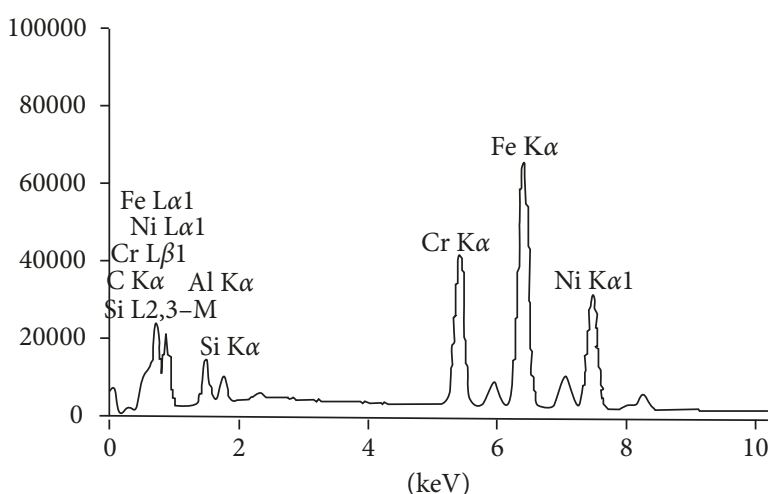

$(\mathrm{keV})$

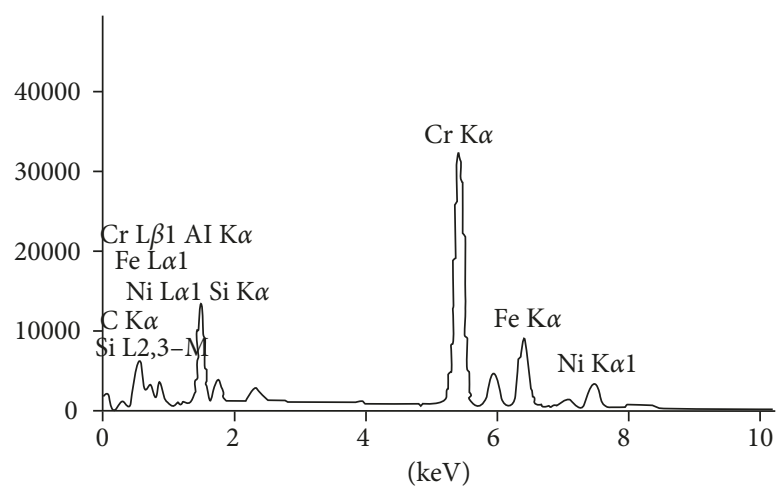

Figure 7: Mapping of phase components (according to Figure 5) with cumulative EDS spectrums.

compositions as those of $\beta-\mathrm{Al}(\mathrm{Ni}, \mathrm{Fe})$ precipitates from the first layer (Figure 6(a), Table 2, point 2 and point 3 ). In the vicinity of this $\mathrm{Ni}$-rich sublayer, a self-forming $\mathrm{Cr}$-rich layer (Figure 6(a), Table 2, point 1) was observed. This sublayer can be used as a barrier blocking aluminium diffusion, because of a low solid solubility of aluminium in Cr-rich layer, as reported by Gao et al. [23].

Alumina $\left(\alpha-\mathrm{Al}_{2} \mathrm{O}_{3}\right)$ and AlN were also formed near the surface. Additionally, aluminide coatings have an ability to form a protective oxide $\mathrm{Al}_{2} \mathrm{O}_{3}$ scale at higher temperatures during oxidation [24]. Aluminium oxide has good protective properties at high temperature, which is advantageous. AlN phase is oxidized to $\alpha-\mathrm{Al}_{2} \mathrm{O}_{3}$, but not directly. The transition oxides are transformed into amorphous $\mathrm{Al}_{2} \mathrm{O}_{3}$ gradually and finally to $\alpha-\mathrm{Al}_{2} \mathrm{O}_{3}$ [25]. Therefore, the presence of the AlN phase on the surface could be also very advantageous.

\section{Summary}

The aluminide protective coatings by the slurry method were successfully formed on austenitic creep-resisting cast steel. The coatings consisted of three-layers having different thicknesses and properties. The thickness of the coatings from the high-temperature processes were very uniform, contrary to the coatings produced using the low temperature, especially in a long time, which were less uniform. The use of the long time of annealing caused growing of the third layer, which was very brittle. The structure and, as a consequence, the properties of the coatings depended on the production parameters. The thickness was the function of time and temperature of the annealing.

The growth of the second layer is mainly induced by the aluminium diffusion from an active mixture and nickel and 
TABLE 3: Average content of chemical elements in phases according to Figure 7.

\begin{tabular}{|c|c|c|c|c|c|c|c|}
\hline \multirow{2}{*}{ Element } & \multicolumn{7}{|c|}{ Content (\% at.) } \\
\hline & Phase 1 & Phase 2 & Phase 3 & Phase 4 & Phase 5 & Phase 6 & Phase 7 \\
\hline $\mathrm{Al}$ & 62.0 & 28.2 & 49.5 & 40.7 & 4.8 & 3.0 & 20.4 \\
\hline $\mathrm{Si}$ & 3.1 & 14.0 & 1.6 & 2.3 & 8.4 & 3.5 & 2.6 \\
\hline $\mathrm{Cr}$ & 6.6 & 31.1 & 8.4 & 12.5 & 22.2 & 19.5 & 53.5 \\
\hline $\mathrm{Fe}$ & 17.8 & 15.6 & 22.2 & 16.2 & 54.7 & 46.3 & 16.5 \\
\hline $\mathrm{Ni}$ & 10.5 & 11.2 & 18.3 & 28.3 & 10.0 & 22.7 & 7.1 \\
\hline Total & & & & & & & 100.0 \\
\hline The main phase & $\mathrm{Al}_{5} \mathrm{FeNi}$ & $\mathrm{CrSi}_{2}$ & $\beta-\mathrm{Al}(\mathrm{Fe}, \mathrm{Ni})$ & $\beta-\mathrm{Al}(\mathrm{Ni}, \mathrm{Fe})$ & $\mathrm{A}(\mathrm{Fe}, \mathrm{Cr}, \mathrm{Si})$ & $\Gamma(\mathrm{Fe}, \mathrm{Ni}, \mathrm{Cr})$ & $(\mathrm{Cr}, \mathrm{Fe})_{7} \mathrm{C}_{3}$ \\
\hline
\end{tabular}

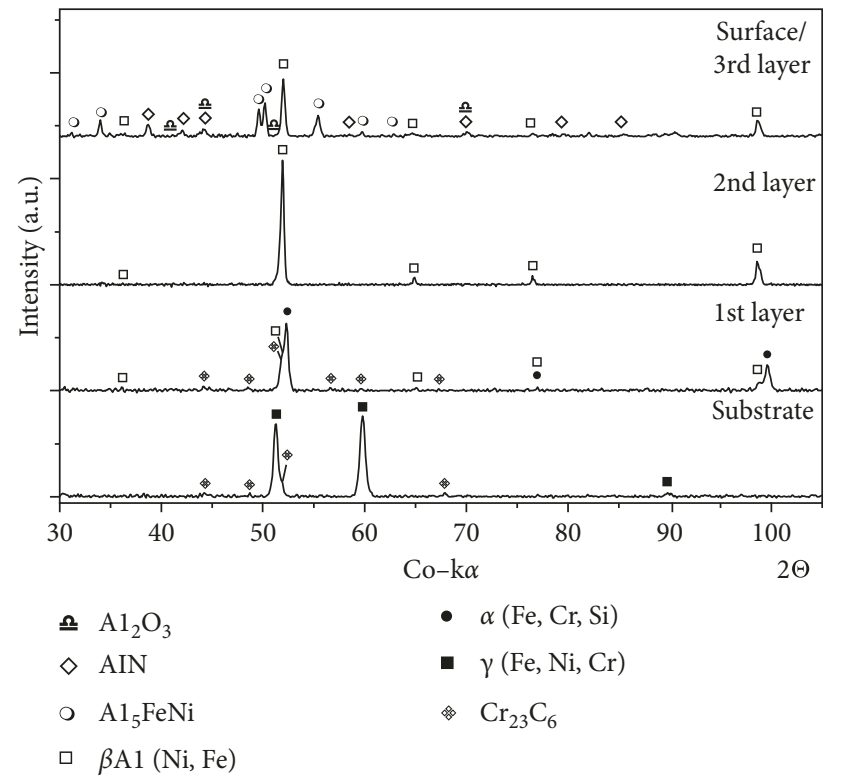

FIGURE 8: XRD patterns (the coating number 4 obtained at $1000^{\circ} \mathrm{C}$, 10 hours, $\mathrm{Al} / \mathrm{Si}=6)$.

iron diffusion from the substrate. The activity of the diffusing elements during the heat treatment is the parameter which determines the type of coating that is obtained. There are two variants: outwards and inwards diffusion coatings. The first one is produced in a low activity of aluminium and leads to the $\beta-\mathrm{Al}(\mathrm{Fe}, \mathrm{Ni})$ phase forming. This case was observed in coatings produced at 900,1000 , and $1068^{\circ} \mathrm{C}$ (Figure 8 ). In the second layer also, the $\mathrm{Cr}(\mathrm{Al}, \mathrm{Si})_{2}$ phase formed in the matrix of the $\beta$ - $\mathrm{Al}(\mathrm{Fe}, \mathrm{Ni})$ phase was observed (Figures $3(\mathrm{~b})$ and 5 ).

The inwards diffusion coating is produced in a high activity of aluminium and leads to the $\mathrm{Ni}_{2} \mathrm{Al}_{3}$ or $\mathrm{Al}_{5} \mathrm{FeNi}$ phase creation. This case was observed in coatings produced at 732 and $800^{\circ} \mathrm{C}$. Phases which contain a higher amount of aluminium were present, for example $\mathrm{Al}_{5} \mathrm{FeNi}$ (sample no. 3 , Figure 9) and $\mathrm{Ni}_{3} \mathrm{Al}_{2}$ (sample no. 3 and no. 7, Figure 10). The $\mathrm{Cr}(\mathrm{Al}, \mathrm{Si})_{2}$ phase was also observed in both the investigated cases.

For various $\mathrm{Al}$ to $\mathrm{Si}$ ratios in the slurry, differences in the structure of the coatings were significant in coatings manufactured at the lower temperature, that is, $800^{\circ} \mathrm{C}$. $\mathrm{The} \mathrm{Al}_{8} \mathrm{Cr}_{5}$

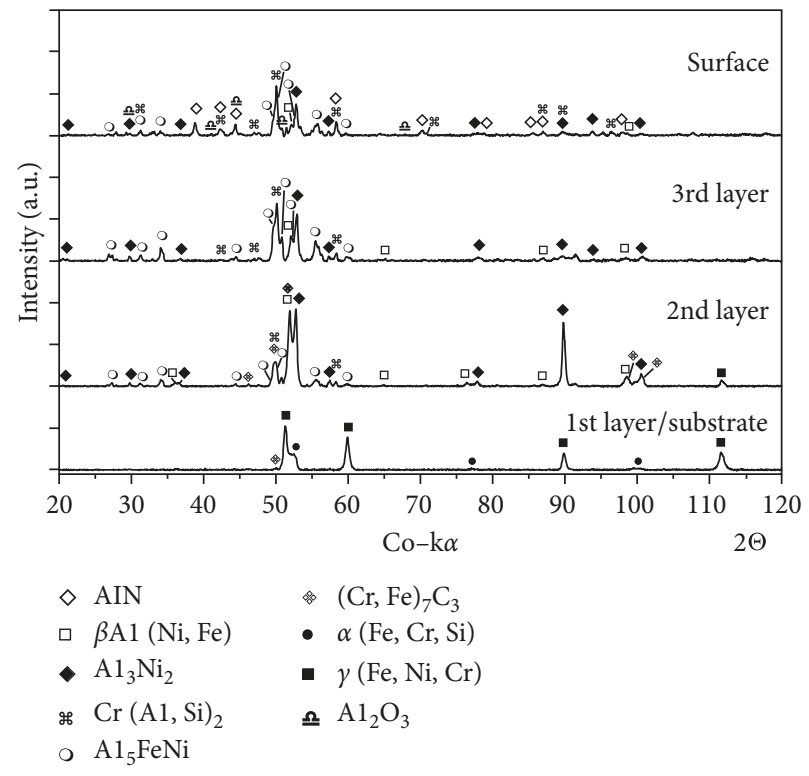

FIGURE 9: XRD patterns (the coating number 3 obtained at $800^{\circ} \mathrm{C}$, 10 hours, $\mathrm{Al} / \mathrm{Si}=6$ ).

phase was created, when the amount of silicon was smaller in the slurry $(\mathrm{Al} / \mathrm{Si}=12)$, and $\mathrm{Al}_{5} \mathrm{FeNi}$ phase was observed, when the amount of silicon in the slurry was higher $(\mathrm{Al} / \mathrm{Si}=6)$. Analysis of the results allowed to develop a simplified model of the coatings showing the influence of the silicon in the slurry (Figure 11).

The Al-Si coatings were designed to protect the hightemperature creep resisting cast steel against carburisation. Assessment of the coatings' behaviour in the carburising atmosphere under thermal shock conditions will be the final verification of their protective properties. The promising results of the preliminary investigations of carburisation and oxidation of coated cast steel have been carried out and presented in the article [26]. The selection of the production parameters leads to the formation of the coating having a suitable structure and properties. The phase composition of the coatings, which is $\mathrm{Al} / \mathrm{Si}$ ratio dependent, can have a significant influence on the resistance against carburisation.

Coatings can be produced on the raw cast surface without any further surface finishing processes. This is a very 


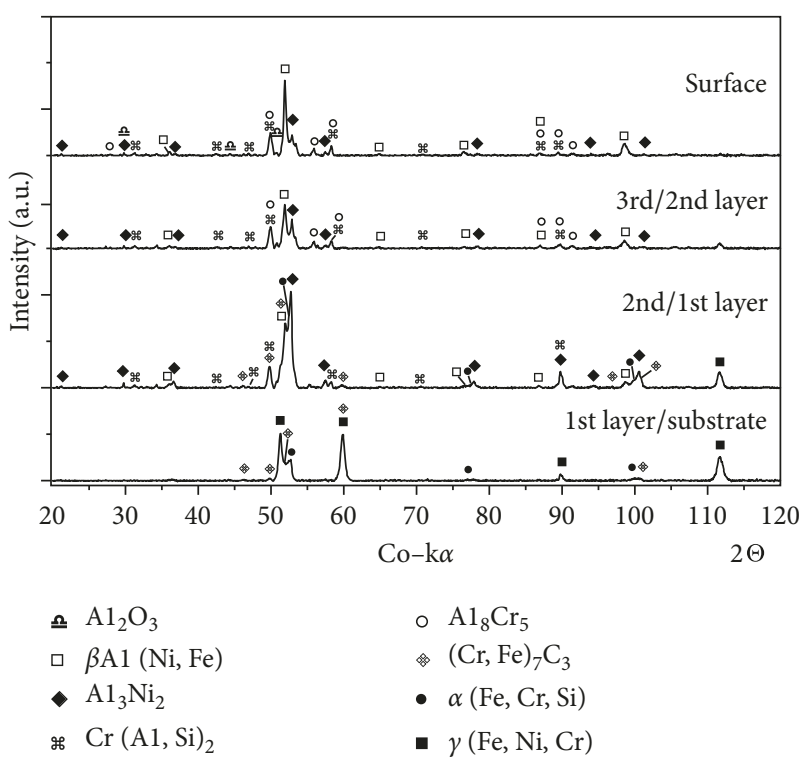

FIGURE 10: XRD patterns (the coating number 7 obtained at $800^{\circ} \mathrm{C}$, 10 hours, $\mathrm{Al} / \mathrm{Si}=12$ ).

important advantage of the applied method, because it simplifies the process of equipment manufacturing and reduces costs.

The advantageous slurry method is more convenient and less harmful than the classic powder methods. This method is also easy to apply and could be used for a local application. Other advantages of this method are a low expenditure of the slurry materials and possibility of producing uniform and high-quality coatings on equipment with a large and complex shape. A very important aspect from an industrial conditions perspective is the increase of the mechanical strength combined with the decreased brittleness of the dried slurry (before annealing), caused by the soluble glass additive. Moreover, the use of the powder of coarser granularity reduces the risk of an explosion.

\section{Conclusions}

(1) Experimental rotatable designs are useful tools for identifying significant process parameters for the aluminide coatings by the slurry method.

(2) Three-layer Si-rich aluminide coatings were obtained on high-temperature creep resisting cast steel using a modified slurry method with soluble glass as the binder in the air atmosphere. Application of the aqueous solution of sodium silicate in the slurry allowed for annealing in an one single step.

(3) The outer layer of the coatings contained Al-rich phases. The middle layer contained intermetallic phases, mainly $\beta-\mathrm{Al}(\mathrm{Ni}, \mathrm{Fe})$. The crystal lattice of the first layer was different from the substrate and from the other layers of the coating. Ferrite was formed from Ni-depleted austenite. This occurred because nickel diffuses from the substrate to the second layer,

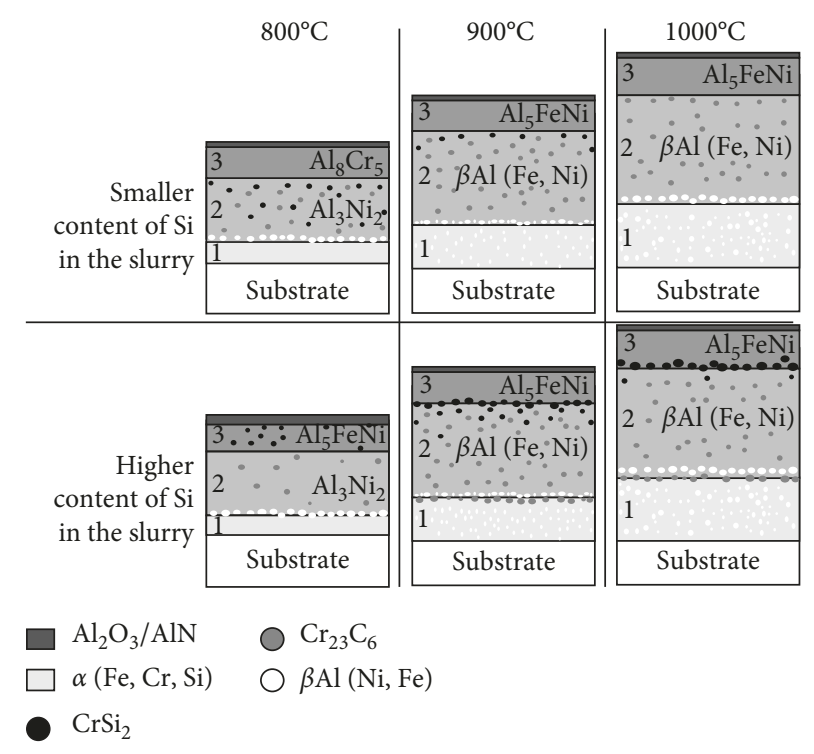

Figure 11: A simplified model of the coatings. Effect of the silicon content in the slurry on the phase composition of the coatings.

and $\mathrm{Ni}$ content was lower in the first layer than in the substrate.

(4) Thickness of the coatings depended on the production parameters (mainly on time and temperature). The ratio $\mathrm{Al} / \mathrm{Si}$ in the slurry (in the applied range) did not have a significant impact on the thickness of the coating. The content of aluminium and silicon in the slurry affected the phase components formed in the coatings.

(5) Hardness value of internal layer was intermediate between the hardness of the middle layer and the base material, which is favourable from the thermal shock resistance viewpoint.

(6) The slurry method is also applicable for materials of a raw cast surface thanks to the presence of a flux in the slurry.

\section{Conflicts of Interest}

The author declares that there are no conflicts of interest regarding the publication of this paper.

\section{References}

[1] J. F. Norton and W. T. Bakker, "Materials for coal gasification plant," Materials at High Temperature, vol. 11, pp. 1-4, 1993.

[2] P. R. Roberge, Handbook of Corrosion Engineering, McGrawHill, New York, NY, USA, 2000.

[3] Z. Zhan, Y. He, L. Li, H. Liu, and Y. Dai, "Low-temperature formation and oxidation resistance of ultrafine aluminide coatings on Ni-base superalloy," Surface and Coatings Technology, vol. 203, no. 16, pp. 2337-2342, 2009.

[4] Z. Xu, J. Dai, J. Niu, L. He, R. Mu, and Z. Wang, "Isothermal oxidation and hot corrosion behaviors of diffusion aluminide coatings deposited by chemical vapor deposition," Journal of Alloys and Compounds, vol. 637, pp. 343-349, 2015. 
[5] D. B. Lee, H. Mitsui, H. Habazaki, A. Kawashima, and K. Hashimoto, "The high temperature sulfidation behavior of Nb-Al-Si coatings sputter-deposited on a stainless steel," Corrosion Science, vol. 38, no. 11, pp. 2031-2042, 1996.

[6] K. L. Wang, F. S. Chen, and G. S. Leu, "The aluminizing and Al-Si codeposition on AISI HP alloy and the evaluation of their carburizing resistance," Materials Science and Engineering: A, vol. 357, no. 1-2, pp. 27-38, 2003.

[7] Y. Wang and W. Chen, "Microstructures, properties and high-temperature carburization resistances of HVOF thermal sprayed NiAl intermetallic-based alloy coatings," Surface and Coatings Technology, vol. 183, no. 1, pp. 18-28, 2004.

[8] A. Kochmańska and J. Kubicki, "Efficiency of protective coatings on high creep resistant cast steel," Archives of Foundry Engineering, vol. 9, no. 2, pp. 129-132, 2009.

[9] A. J. Rasmussen, A. Agüero, M. Gutierrez, and M. J. L. Østergård, "Microstructures of thin and thick slurry aluminide coatings on Inconel 690," Surface and Coatings Technology, vol. 202, no. 8, pp. 1479-1485, 2008.

[10] C. Boulesteix, B. Grégoire, and F. Pedraza, "Oxidation performance of repaired aluminide coatings on austenitic steel substrates," Surface and Coatings Technology, vol. 326, pp. 224-237, 2017.

[11] J. Bermejo Sanz, R. Roussel Garcia, V. Kolarik, and M. Juez Lorenzo, "Influence of the slurry thickness and heat treatment parameters on the formation of aluminium diffusion coating," Oxidation of Metals, vol. 88, pp. 179-190, 2017.

[12] X. Montero, M. C. Galetz, and M. Schutze, "A novel type of environmentally friendly slurry coatings," JOM, vol. 67, no. 1 , pp. 77-86, 2015.

[13] Y. Tamarin, Protective Coatings for Turbine Blades, ASM International, Novelty, OH, USA, 2002.

[14] A. Agüero, M. Gutiérrez, R. Muelas, D. Plana, A. Román, and M. Hernández, "Laboratory corrosion testing of coatings and substrates simulating coal combustion under a low $\mathrm{NO}_{\mathrm{x}}$ burner atmosphere," Materials and Corrosion, vol. 65, no. 2, pp. 149-160, 2014.

[15] A. Agüero, M. Gutiérrez, R. Muelas, and K. Spiradek-Hahn, "Overview of steam oxidation behaviour of $\mathrm{Al}$ protective oxide precursor coatings on P92," Surface Engineering, vol. 34, no. 1 , pp. 30-39, 2016.

[16] West Pomeranian University of Technology in Szczecin, "Method of manufacturing coatings protecting metal parts exposed to carburization, oxidation and thermal shock," PL Patent 209678, 2011.

[17] G. W. Oehlert, A First Course in Design and Analysis of Experiments, University of Minnesota, Minneapolis, MN, USA, 2010.

[18] K. Thompson, Unleashing the Power of COMPASS, 2015, http://www.thermoscientific.com/content/dam/tfs/ATG/CAD/ CAD\%20Documents/Videos\%20\&\%20Webinars/Microanalysis\%20 and\%20Electron\%20Microscopy/WS52733-Power-of-COMPASS. pdf.

[19] A. Kochmańska, J. Kubicki, and P. Kochmański, "Protective Al-Si coatings obtained on high-temperature creep resistance cast steel," Materials Science, vol. 12, no. 2, pp. 120-123, 2006.

[20] A. Kochmańska and M. Garbiak, "High-temperature diffusion barrier for Ni-Cr cast steel," Defect and Diffusion Forum, vol. 312-315, pp. 595-600, 2011.

[21] H. C. Akuezue and D. P. Whittle, "Interdiffusion in $\mathrm{Fe}-\mathrm{Al}$ system: aluminizing," Metal Science, vol. 17, no. 1, pp. 27-33, 1983.
[22] T. L. Hu, H. L. Huang, D. Gan, and T. Y. Lee, "The microstructure of aluminized type 310 stainless steel," Surface and Coatings Technology, vol. 201, no. 6, pp. 3502-3509, 2006.

[23] F. Gao, Q. Yang, R. Liu, and X. Huang, "Oxidation resistance of novel multilayer coatings for gas turbine components," Surface Engineering, vol. 30, no. 9, pp. 624-635, 2014.

[24] H. Svensson, J. Angenete, and K. Stiller, "Microstructure of oxide scales on aluminide diffusion coatings after short time oxidation at $1050^{\circ} \mathrm{C}$," Surface and Coatings Technology, vol. 177-178, pp. 152-157, 2004.

[25] R. Yue, Y. Wang, Y. Wang, and C. Chen, "SIMS study on the initial oxidation process of AlN ceramic substrate in the air," Applied Surface Science, vol. 148, no. 1-2, pp. 73-78, 1999.

[26] A. Kochmańska, "Hot corrosion resistance properties of Al-Si coatings obtained by slurry method," Defect and Diffusion Forum, vol. 326-328, pp. 273-278, 2012. 


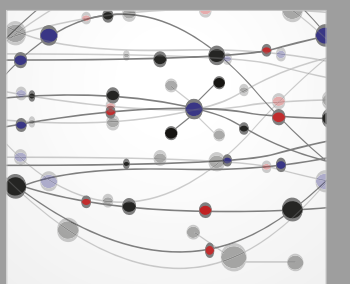

The Scientific World Journal
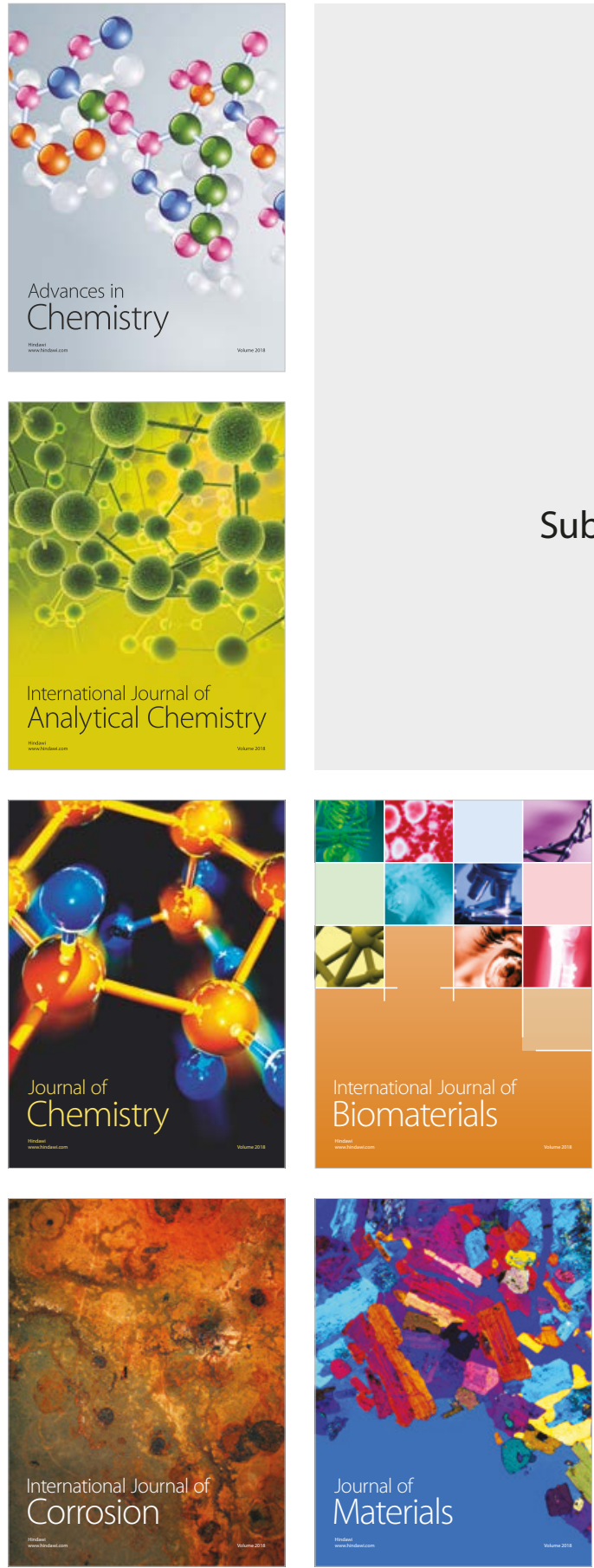

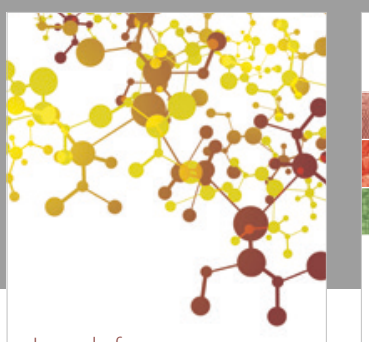

Journal of

Applied Chemistry
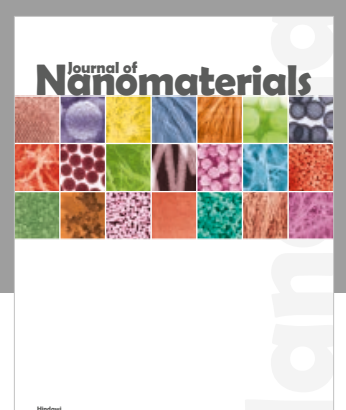

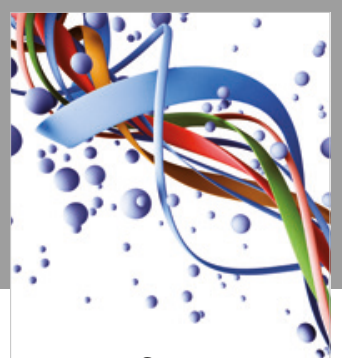

Scientifica

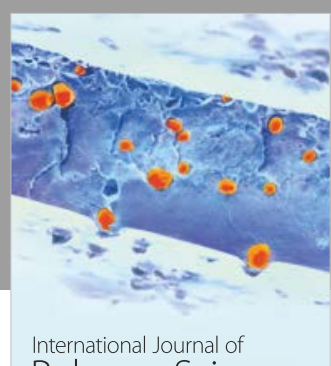

Polymer Science

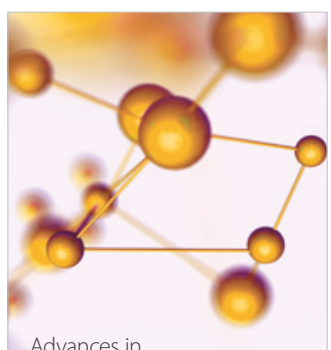

Physical Chemistry
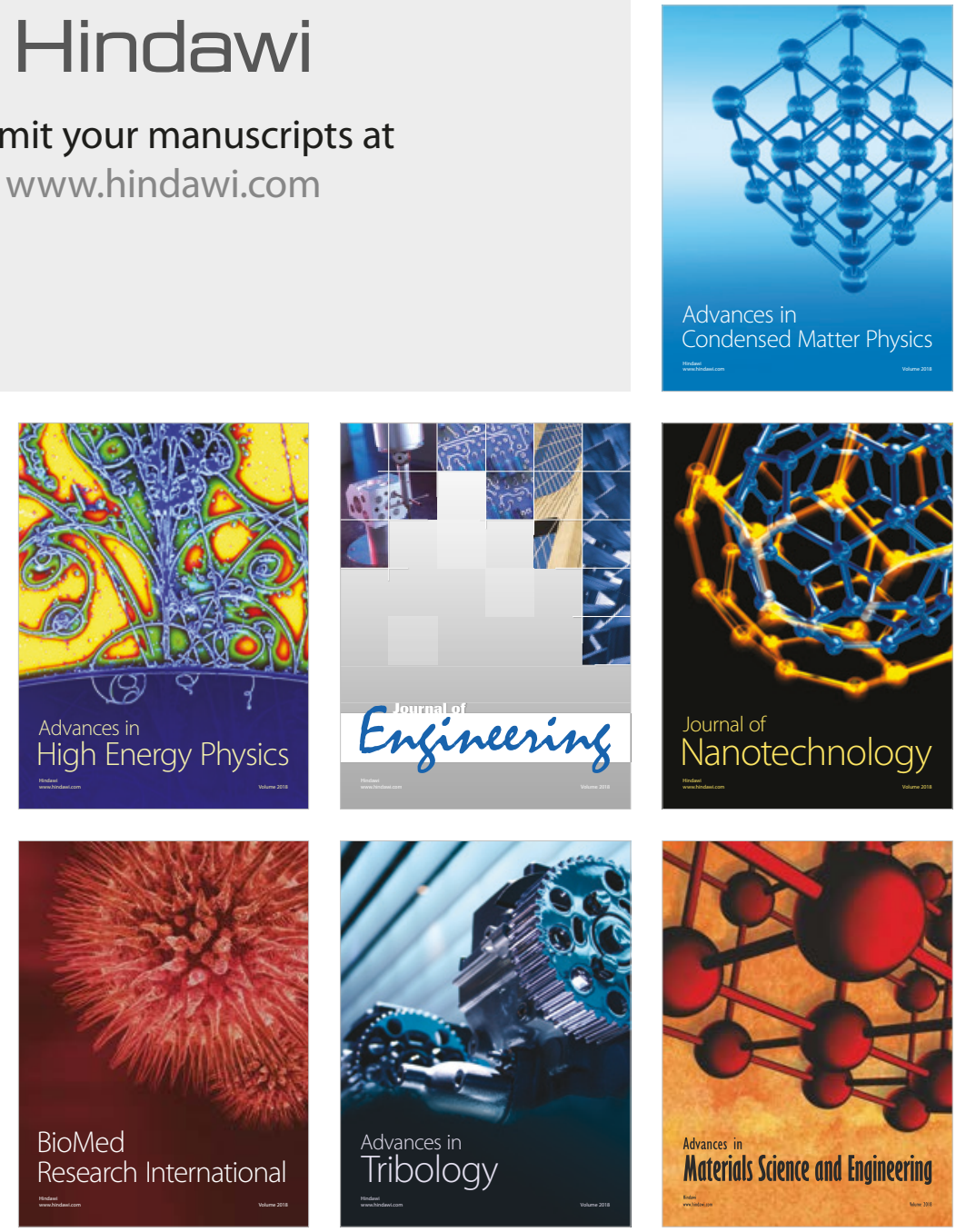